\title{
The Limited Power of Voting to Limit Power
}

\author{
HONG GENG \\ Laboratory for Experimental Economics, University of Bonn \\ ARNE ROBERT WEISS \\ Center for Empirical Research in Economics and Behavioral Sciences, University of Erfurt \\ IRENAEUS WOLFF \\ University of Konstanz, Thurgauer Wirtschaftsinstitut (TWI)
}

\begin{abstract}
In this paper, we experimentally approach the question of which aspects of a voting procedure are able to restrict elected candidates' willingness to use their power in an opportunistic way. For this purpose, we rule out re-election concerns and analyze whether the presence of a vote by itself matters for the exercise of power. We compare two kinds of electoral campaigns: self-descriptions of personality and promises regarding prospective in-office behavior. We find that social approval as conveyed by a vote does not suffice to induce pro-social choices by elected candidates. On the other hand, when campaigns are promisebased, elected candidates transfer more to their recipients than candidates selected by a random draw even though promises do not differ. This refutes explanations based on a taste for consistency or costs of lying. In contrast, the fact
\end{abstract}

Hong Geng, Laboratory for Experimental Economics, University of Bonn, Germany (honggeng@gmx.de). Arne Robert Weiss, University of Cologne \& Center for Empirical Research in Economics and Behavioral Sciences, University of Erfurt, Germany (arne.weiss@wiso.uni-koeln.de). Irenaeus Wolff, University of Konstanz, Germany / Thurgauer Wirtschaftsinstitut (TWI), Kreuzlingen, Switzerland (wolff@twi-kreuzlingen.ch).

We thank Gari Walkowitz as well as Stephan Tontrup for their support in designing the experiment and Mareike Hoffmann as well as Fu Hao for running the German sessions and the follow-up sessions in China, respectively. We are indebted to Jia Jiamin and the industrious staff at the Herbert A. Simon, and Reinhard Selten Behavioral Decision Research Lab for their support as well as to CEREB and the Bonn Laboratory for Experimental Economics for funding the experiment. Our thanks further go to Katharine Bendrick, Mareike Hoffmann, Bettina Rockenbach, Özgür Gürerk, members of CEREB, and to the associate editor and two anonymous referees, for valuable comments on earlier versions of the paper. 
that the correlation between dictators' promises and their beliefs on voter expectations is considerably strengthened in the presence of a vote offers support to a guilt-aversion hypothesis. However, this support is qualified by the correlation between dictators' second-order beliefs and their choices, which is weaker than predicted. Overall, our results suggest the power of voting to limit the self-oriented exertion of power is limited and context specific.

\section{Introduction}

Power is a double-edged sword. It is an essential instrument to resolve collective-action problems; at the same time, it may be abused to the power holder's own advantage. ${ }^{1}$ In many cases of organized human interaction, power is transferred through elections. Elections may serve as a disciplinary device by threatening dismissal from office (e.g., Bardhan and Yang 2004; for experimental evidence, cf. Weiss 2011). Elections may also act as a means of selection, possibly leading to the selection of the leader who is most capable (e.g., Carrillo and Mariotti 2001), whose preferences are most in line with the constituency's own preferences (Maskin and Tirole 2004) or even who may be motivated to serve the public (Cooter 2003, Besley 2005). However, this may not be the end of the story. Possibly, not only the outcome of elections matter, but the procedure of voting itself. In this paper, we set out to analyze how the mere presence of a voting procedure may shape behavior: we compare the introduction of an election with either of two types of electoral campaigns - which differ as to whether the campaign is related to in-office choices-to a random appointment of leaders. This way, we take a first step toward answering the question of what it is in a voting procedure that is able to stop elected leaders from taking full advantage of their powerful position.

This question bears relevance to real-world politics: not all abovementioned aspects will be present in every election. Sometimes, a politician can no longer be motivated by re-election concerns, for example, at the end of a fixed maximum number of terms in office as for presidents in the United States. Also, voters may not always be able to infer a candidate's political preferences as either a relevant political track-record is not yet established or because electoral campaigns convey a certain picture of the candidate's personality, more than of what that candidate's agenda is (cf. the long-standing argument on the nature of campaigns in political science, e.g., Miller, Wattenberg, and Malanchuk 1986, Stokes 1966, King 2002; for voter preferences over campaign types, see e.g., Lipsitz et al. 2005). We therefore abstract from re-election concerns, and candidates are unknown

${ }^{1}$ This fundamental dilemma was already noted, forcefully, by Locke (1988). 
to the voters. The question we set out to answer in the stylized world of a laboratory setting is under which form of electoral campaigns voters may reasonably expect to be better off if they can elect their leader compared to a situation without a ballot. Specifically, we analyze two types of electoral campaigns. One of them is personality based; being elected under this protocol may convey a feeling of social appreciation on behalf of the voters, which is an integral part of any voting procedure. By looking at the effects of this type of campaign, we aim to study whether a voting procedure per se can influence the self-oriented exercise of power. This voting procedure may matter especially if it decreases social distance between the leader and the constituency (Hoffman, McCabe, and Smith 1996, 1999, Bohnet and Frey 1999). The other type of electoral campaign is based on explicit promises on in-office behavior. Promise-based voting may matter if promises are considered more than cheap-talk and promises are affected by electoral competition.

Our research question has received little academic attention despite a considerable amount of evidence that participatory procedures can have strong effects on behavior. Relevant literature on ballot voting (Ostrom, Walker, and Gardner 1992, Maier-Rigaud and Apesteguia 2003, Tyran and Feld 2006, Dal Bó, Foster, and Putterman 2008) and foot voting (Gürerk, Irlenbusch, and Rockenbach 2006) has shown that these procedures substantially enhance cooperation within groups. To the best of our knowledge, there are only three papers concerned with the power-limiting effects of elections in a hierarchical context. Weiss (2011) shows elected power-holders to send back considerably more than randomly drawn power-holders in a trust relationship; this effect is found even in the last election period when reelection cannot motivate incumbents anymore. Walkowitz and Weiss (2011) find a similar-although less pronounced—effect in the same situation even if reliable reputation building is ruled out. Most closely related to our paper, Corazzini, Kube, and Maréchal (2007) find elected allocators to promise and send more to recipients in a dictator-recipient relationship than randomly appointed allocators, as long as their approval rates are higher than what is minimally required to win the election. However, in all of the above experiments, the effects of the voting procedure are confounded with commitment to promises (Ellingsen and Johannesson 2004, Vanberg 2008) and guilt-aversion (Charness and Dufwenberg 2006, Battigalli and Dufwenberg 2007), as well as dynamic considerations or interaction effects with trusting behavior in the case of Weiss (2011) and Walkowitz and Weiss (2011). The purpose of this study is to single out the effects of social approval and of promises on in-office behavior.

In our design, we vary the election procedure in a $2 \times 2$ factorial betweensubject design. In all treatments, one of two candidates is selected to become-effectively - the dictator in a dictator subgame with three recipients and efficiency gains from nonselfish choices. This is meant to reflect in a stylized fashion the power relationship between leaders and their constituency in the presence of conflicts of interest, in conjunction with the 
idea that selfish acts of leaders often will be harmful to society as a whole. Candidates are selected either by majority vote of the future recipients or by random draw, to analyze the effects of the presence of a voting procedure. As pointed out before, we also vary the way candidates may present themselves to their electorate before the selection stage, to reflect the different types of electoral campaigns.

The experiments were run in Chengdu, China. Our results show that a voting procedure without electoral promises does not limit the self-oriented exercise of power. In addition, we ran sessions of the treatments without promises in Erfurt, Germany, to test the robustness of these results in an environment in which decisions by majority vote are a common way to decide on organizational as well as political matters. If at all, dictators' transfers are higher in both countries when there is no vote. In fact, German recipients expect this to be the case. We discuss this unexpected result in light of previous research on entitlements and other-regarding behavior (e.g., Hoffman et al. 1994). Our result suggests that in the voting context the creation of entitlements may be more important than the diminishing of social distance or other implicit reciprocity motives as suggested by Hoffman, McCabe, and Smith $(1996,1999)$. On the other hand, when the voting procedure is coupled with a promise concerning in-office behavior, dictators' transfers are higher than under the corresponding random mechanism, in line with the predictions of a simple signaling model with guilt-aversion as introduced by Dufwenberg and Charness (2006) and corroborating the earlier results of Corazzini, Kube, and Maréchal (2007). In contrast to Corazzini, Kube, and Maréchal (2007), our data even show that higher transfers are not due to higher promises made in response to electoral competition. Instead, voting substantially strengthens the correlation between dictators' promises and their beliefs with respect to voters' expectations, in line with the guiltaversion hypothesis. Our simple model generally organizes the data well, with two exceptions: promises do not differ between the random and the voting regimes, and voter expectations with respect to transfers are not pessimistic enough. However, the fact that transfers are different despite similar promises must be counted as clear evidence that the mechanism connecting promises and transfers is not simply a taste for consistency or an aversion to lying. Therefore, our results make a valuable contribution to the current debate on the driving factors in situations in which promises play a role (cf. Charness and Dufwenberg 2006, 2010, Vanberg 2008, Ellingsen et al. 2010).

The paper is organized as follows: In Section 2, we describe the experimental design and procedure. Section 3 provides the subgame-perfect Nashequilibrium for money-maximizing agents as well as behavioral hypotheses on how behavior may differ from this prediction once we depart from standard game-theoretic assumptions. In addition, we sketch a simple signaling model with guilt-aversion to derive our hypotheses for the treatments involving electoral promises. In Section 4, we present our results and discuss them in Section 5. 


\section{Experimental Design and Procedure}

\subsection{Experimental Design}

For our study, we introduced four variants of a five-player game with two candidates and three recipients, who were also voters in the voting treatments. As we were interested in behavior in the absence of re-election concerns, we used a one-shot between-subject design, that is, every subject played only one variant of the game and subjects played the game only once. The four variants of the game were related in a $2 \times 2$ fashion and denoted by Vote-D, RAND-D, Vote-P, and RAND-P. Each game consists of three stages, an electoralcampaign stage, a selection stage, and an allocation stage. The corresponding $\mathrm{D}$ (description)- and $\mathrm{P}$ (promise)-games differ in the electoral-campaign stage, whereas the corresponding VOTE- and RAND-games differ in the selection stage. A detailed description of each stage follows.

The P-games examine the role of elections in determining electoralcampaign promises and how these promises affect postelectoral distributive choices of successful candidates. The D-games replace the numerical promises with a description of candidates' personalities to single out the effect of a vote in the absence of electoral promises. For this purpose, the election taking place in VOTE-D is based on something as unrelated as possible to the distributional decision. In doing so, we also rule out signaling opportunities for the candidates concerning in-office behavior; at the same time, for elections to retain their characteristic as potentially conveying social approval, the procedure must be meaningful for voters and candidates. The candidates need to relate their electoral performance to the personality descriptions, for which they need to expect voters' choices to be nonarbitrary. The nonrandom item choices of candidates as well as postexperimental questionnaire data suggest these aims were achieved. ${ }^{2}$

The individual stages of the games were the following:

- in the electoral-campaign stage of the D-games, the candidates chose a ranked list of three out of the following eight positively connoted terms: "optimistic," "erudite," "creative," "musical," "sportive," "lively," "diligent," and "fond of traveling." This personal description was displayed to all three voter-recipients. In the P-games, candidates chose a numerical promise $y, y \in\{0,1, \ldots, 100\}$, instead of the personality description.

- in the selection stage of the RAND-games, one of the two candidates was chosen by chance through a computer-generated random draw. In

\footnotetext{
${ }^{2}$ In the Vote-D sessions, a Chi-square goodness-of-fit test rejects the null-hypothesis of a random choice by dictators at a level of $p=0.008$, the two candidates of a group never chose identical personality descriptions, and in the postexperimental questionnaire, $87 \%$ of the recipients indicated that they perceived the candidates' statements as important for their voting decision.
} 
the VoTE-games, each voter-recipient had to choose one of the two candidates. The winning margin of the selected candidate was not disclosed.

- in the allocation stage, selected candidates chose any amount $t, t \in\{0$, $1, \ldots, 100\}$, to allocate to the recipients, keeping the remainder of the 100 points for themselves. Recipients' payoff was given by the amounts transferred by the selected candidate in their group. The candidate not selected received a random payoff from the same interval as selected candidates' decision range. This randomness was introduced to avoid anchoring effects or creation of a focal point for the selected candidate's choice.

As each recipient receives $t$ but the dictator pays only once, our design implies a multiplicator of 3 for the amount $t$ transferred by the dictator. Efficiency, as measured by total payoffs of selected candidates and voterrecipients, therefore increases with transfers $t$. We incorporate welfare gains from nonselfish choices into our model as we believe that if politicians refrain from lining their own pockets, we may expect society to benefit more than the politician would lose. The multiplicator of 3 was chosen to ease calculations, as transfers would translate into individual benefits in a one-to-one fashion. ${ }^{3}$

Given that selected candidates effectively play a dictator game between themselves and their voter-recipients, we call the former the dictators and the latter the recipients in the remainder of the paper. In the experiment itself, we used the terms "president" for dictators, "citizens" for voter-recipients, and "candidates" for candidates. ${ }^{4}$ A translated version of the instructions can be found in Appendix.

As we have not found significant treatment differences between the Vote-D and RAND-D sessions in our main subject pool in China, where voting procedures are rarely used in political and organizational contexts, we wanted to test for the robustness of this lack of difference. To address this issue, we ran the two treatments again in Germany, were democratic procedures are far more common, to check whether this would lead to different results.

To gain further insight into the relevance of the voting procedure, we also collected hypothetical transfers from the unselected candidates as well as recipients' expectations on the dictator's transfer. To elicit hypothetical decisions as closely to actual decisions as possible but without actually employing

\footnotetext{
${ }^{3}$ Because the one-shot game rules out learning opportunities for the participants, mental demands should be as low as possible. Arguably, a multiplicator of 3 even poses less mental demands than a unity multiplicator as dictators do not need to do any calculation to compare their own profit to each recipient's profit.

${ }^{4}$ In local language, we employed the following terms in the experiment (Chinese, German): president: (zhǔxí), Bürgervorsitzender; citizen: (gōngmín), Bürger; candidate: (hòuxuănrén), Kandidat.
} 
the strategy method (Selten 1967), we let the unselected candidates state directly before announcing the election result how much they would transfer if they were elected as dictator. ${ }^{5}$ At the time of answering the question, they were not aware of whether they had been chosen or not. ${ }^{6}$ For the same reason, the elicitation of recipients' beliefs was done after announcing the winner of the election or the random draw. As soon as they were informed about the result of the selection, recipients were asked to estimate how many points they would get from the selected dictator. In the P-sessions, we also elicited second-order beliefs of the selected dictators to measure the relation between promises and second-order beliefs that may trigger guilt. ${ }^{7}$ Note that we elicited second-order beliefs only after dictators chose how many points to transfer to their group, without announcing this question beforehand; in this way, numerical promises instead of personal characteristics are the only difference between the P-treatments and their corresponding D-treatments.

\subsection{Procedure}

The Chinese $\mathrm{D}(\mathrm{P})$-sessions were run in November 2007 (January 2009) at the Herbert A. Simon and Reinhard Selten behavioral decision research lab of the Southwest Jiaotong University in Chengdu, China. The German Dsessions were run in January 2008 at the Laboratory for Experimental Economics (eLab) at the University of Erfurt. For each D-treatment, we collected 15 independent observations in China and 10 in Germany, whereas we collected 20 independent observations for each P-treatment. ${ }^{8}$ Therefore, 350 students participated in the Chinese sessions and 100 students in the German sessions. Test questions made sure that subjects were aware of the one-shot play, the power asymmetry in their group as well as of how profits were calculated. The experiment started only when all subjects in the session correctly answered all test questions. Each experimental session lasted about 1 hour including instructions and payments. On average, Chinese students earned about 42.5 RMB (approximately 4 euros), and German students earned about 11.5 euros. The exchange rates between points and cash/local currency were set according to local standards. The experiment was programmed in z-Tree (Fischbacher 2007).

\footnotetext{
${ }^{5}$ We opted against employing the strategy method for eliciting decisions from both the selected and the nonselected candidate as we want to stay as closely as possible to a realworld voting context.

${ }^{6}$ The text unselected candidates see on their screen is "It will be announced soon which candidate has been elected/randomly drawn as president. Please insert how many points you will transfer to the citizens if you have been elected/drawn as president."

${ }^{7}$ The text dictators see on their screen is "The three citizens in your group are estimating how many points you will allocate to them. Please estimate the average points of the estimation of the three citizens."

${ }^{8}$ We thank Peng Cheng for running the P-sessions for us. These sessions are also part of his diploma thesis, supervised by Prof. Dr. Armin Falk of the University of Bonn.
} 


\section{Theoretic Solutions and Behavioral Hypotheses}

\subsection{Payoffs and Game-Theoretic Solution}

Payoff functions for the dictator $\left(\pi_{d}\right)$, voter-recipients $\left(\pi_{v}\right)$ and the unselected candidate $\left(\pi_{l}\right)$ are given by

$$
\begin{aligned}
\pi_{d} & =100-t, \\
\pi_{v} & =t, \quad \text { and } \\
\pi_{l} & \sim U[0,100] .
\end{aligned}
$$

The unique subgame-perfect equilibrium prediction in pure strategies for rational money-maximizing agents is that both candidates announce any arbitrary list (in the D-games) or number (in the P-games), the voter-recipients in the P-games choose any arbitrary candidate, and the selected dictator keeps the entire 100 points for himself, that is $t=0$.

In light of the evidence from related games, however, this prediction does not seem to be very reliable (see, e.g., Forsythe et al. 1994, for evidence of giving behavior in dictator games). Therefore, we will rest our research hypotheses on some of the arguments brought forward in the literature. In a first step, we sketch a simple signaling model with guilt-aversion as introduced by Charness and Dufwenberg (2006) and further developed in Battigalli and Dufwenberg (2007) to underpin our hypotheses for the P-games. ${ }^{9}$ We then present two hypotheses for the D-games, resting them on the results of earlier experimental studies.

\subsection{Sketch of a Signaling Model with Guilt-Averse Candidates}

For our simple model, we assume "selfish" and "altruistic" candidate types, with bliss points $T_{S}$ and $T_{A}, 0 \leq T_{S} \leq T_{A} \leq 1$, respectively, where the bliss points stem from candidates' preferences over income distributions. We further assume that utility losses from deviating from the respective bliss point by the same amount are comparable for "selfish" and "altruistic" types. More specifically, we let the distributional utility of an elected $i$-type player, $i \in\{A$, $S\}$, depend on the player's transfer choice $t_{i}$ in the following way:

$$
U_{i}^{\text {dist }}\left(\alpha, t_{i}\right)=\alpha-\left(T_{i}-t_{i}\right)^{2},
$$

where $\alpha$ is the (maximum) value of being in office and controlling the allocation decision, net of opportunity costs. On a second dimension, candidates suffer from guilt-aversion in the same way as in Charness and Dufwenberg (2006). This assumption transforms our game into a psychological game as defined by Geanakoplos, Pearce, and Stacchetti (1989). By their promise, $y_{i}$, candidates may induce a change in recipients' beliefs about transfers, $\tau\left(y_{i}\right)$.

\footnotetext{
${ }^{9}$ We refrain from spelling out the model and the corresponding derivations in full detail as the focus of this paper is clearly empirical.
} 
We denote candidates' beliefs about recipients beliefs by $\hat{\tau}\left(y_{i}\right)$ and posit the following utility function:

$$
U_{i}\left(\alpha, t_{i}, \hat{\tau}\left(y_{i}\right)\right)=U_{i}^{\mathrm{dist}}\left(\alpha, t_{i}\right)-g\left(t_{i}, \hat{\tau}\left(y_{i}\right)\right)\left(\hat{\tau}\left(y_{i}\right)-t_{i}\right), \quad i \in\{A, S\},
$$

where

$$
g\left(t_{i}, \hat{\tau}\left(y_{i}\right)\right)=\left\{\begin{array}{l}
\gamma, t_{i}<\hat{\tau}\left(y_{i}\right), \\
0, \text { otherwise }
\end{array}\right.
$$

and $\gamma$ is the sensitivity-to-guilt parameter common to both candidate types. Voters' objective function is simply given by $U_{v}\left(t_{j}\right)=t_{j}$, where $j$ is the successful candidate. Therefore, voters always vote for the candidate whose promise leads to the higher expected transfer. Finally, we focus on first-order beliefs that (weakly) increase in promises, that is, we posit $\partial \tau\left(y_{i}\right) / \partial y_{i} \geq 0, \forall y_{i}$.

Before we present potential equilibria of our game, let us analyze the optimal choice of an elected $i$-type. Optimization over $t_{i}$ yields the following best-response to second-order beliefs:

$$
t_{i}^{*}\left(\hat{\tau}\left(y_{i}\right)\right)= \begin{cases}T_{i}+\gamma / 2, & y_{i}: \hat{\tau}\left(y_{i}\right) \geq T_{i}+\gamma / 2, \\ \hat{\tau}\left(y_{i}\right), & y_{i}: T_{i} \leq \hat{\tau}\left(y_{i}\right)<T_{i}+\gamma / 2, \\ T_{i}, & \text { otherwise. }\end{cases}
$$

Therefore, the optimization problem faced by a candidate of type $i$ is to choose $y_{i}$ as to maximize

$$
\begin{gathered}
E U_{i}\left(y_{i}\right)=\left[f_{S} p_{i}\left(y_{i}, S\right)+f_{A} p_{i}\left(y_{i}, A\right)\right]\left(\alpha-\left[T_{i}-t_{i}^{*}\left(\hat{\tau}\left(y_{i}\right)\right)\right]^{2}\right. \\
\left.-g\left(t_{i}^{*}\left(\hat{\tau}\left(y_{i}\right)\right), \hat{\tau}\left(y_{i}\right)\right)\left[\hat{\tau}\left(y_{i}\right)-t_{i}^{*}\left(\hat{\tau}\left(y_{i}\right)\right)\right]\right),
\end{gathered}
$$

where $f_{j}$ is the probability of running against a $j$-type candidate and $p_{i}\left(y_{i}, j\right)$ is $i$ 's probability of winning against that candidate when choosing $y_{i}$.

\subsubsection{Clearly Separated Types}

There are two cases we have to distinguish. In this section, we focus on the case of "clearly separated" player types whose bliss points are far apart, with $T_{A}>T_{S}+\gamma / 2$. We will discuss the case $T_{A} \leq T_{S}+\gamma / 2$ in the following section. Under the assumption of clearly separated types, it is tedious but straightforward to show that for no type can it be optimal to choose a promise $y_{i}$ associated with a second-order belief $\hat{\tau}\left(y_{i}\right)$ such that $\hat{\tau}\left(y_{i}\right)<T_{i}+\gamma / 2$. In other words, both types will promise at least the maximum they would be willing to comply with. This is due to the possibility of meeting another candidate of the same type. This possibility drives promises up in the same way as prices are driven down under Bertrand competition: no promise $y^{\prime}$ such that $T_{i}<\hat{\tau}\left(y^{\prime}\right)<T_{i}+\gamma / 2$ can be an equilibrium promise, as by choosing the credible(!) promise $y^{\prime}+\varepsilon$, a candidate could increase the probability of being elected by $f_{i} / 2$ while shrinking the prize only by an arbitrarily small $\varepsilon$. The question to be answered now is whether we may expect a promise-separating 
equilibrium such that each type chooses $y_{i}$ so as to induce a first-order belief of $\tau\left(y_{i}\right)=T_{i}+\gamma / 2 .^{10}$

For a promise-separating equilibrium to exist, no type may have an incentive to mimic the other type, ceteris paribus. This will obviously hold for altruists; for selfish candidates, it will only hold if the guilt-aversion parameter $\gamma$ is large enough. Namely, this will be the case if the expected utility of promising $T_{S}+\gamma / 2$ and complying with that promise is at least as high as the expected utility of promising $T_{A}+\gamma / 2$ and transferring $T_{S}+\gamma / 2$ in case of a successful electoral campaign: ${ }^{11}$

$$
\frac{f_{S}}{2}\left[\alpha-\left(\frac{\gamma}{2}\right)^{2}\right] \geq\left(f_{S}+\frac{f_{A}}{2}\right)\left[\alpha-\left(\frac{\gamma}{2}\right)^{2}-\gamma\left(T_{A}-T_{S}\right)\right] .
$$

In other words, in a promise-separating equilibrium, selfish types know they will only stand a chance if they meet another selfish type. However, they will stick to a "selfish promise" as the psychological costs from experiencing guilt in case of an "altruistic promise" (which a selfish type would never comply with) outweigh the substantial increase in the probability of a successful electoral campaign.

In addition, there are a multitude of promise-pooling equilibria with uninformative promises. Without loss of generality we focus on a subset of equilibria, placing the following restriction on voter beliefs: as long as it would be optimal for a certain type to deliver on her promise whenever this promise is taken at face value, voters will believe this type to keep the promise. This does not imply that voters' expectation must equal the given promise, as their expectation is a weighted average over first-order beliefs over all types (and other types may not comply with the promise), but it rules out equilibria in which promises are far below actual transfers. Under this restriction, equilibrium behavior has the following properties:

- promises $y_{i}$ are generated by the same (potentially degenerate) random process for both types, which has a lower limit $\underline{y}$ with $\underline{y} \geq T_{A}$.

- voters expect selfish types to choose the maximum they would be willing to transfer, $t_{S}=T_{S}+\gamma / 2$ and altruists to choose their bliss point, $t_{A}=T_{A}$. Therefore, voters' expected transfer is given by

$$
\tau(y)= \begin{cases}f_{S}\left(T_{S}+\gamma / 2\right)+f_{A} T_{A}, & \forall y \geq T_{A}, \\ T_{S}, & \text { otherwise. }\end{cases}
$$

- expectations are rational, such that $\hat{\tau}\left(y_{i}\right)=\tau\left(y_{i}\right)=E(t), t_{S}=T_{S}+$ $\gamma / 2$, and $t_{A}=T_{A}$, and voters choose randomly between candidates

\footnotetext{
${ }^{10}$ Note that by Equation (2) "transfer-separation" must hold if types are "clearly separated": altruists will at least transfer $T_{A}$, whereas selfish types will not transfer more than $T_{S}+\gamma / 2$. ${ }^{11}$ Equation (3) can be easily solved for $\gamma$, yielding the following inequality that eludes a simple intuitive interpretation: $\gamma \geq-2\left(1+f_{S}\right)\left(T_{A}-T_{S}\right)+\sqrt{\left[2\left(1+f_{S}\right)\left(T_{A}-T_{S}\right)\right]^{2}+4 \alpha}$.
} 
whose promises fall within the same bracket, that is, within $\left[0, T_{A}\right)$ or $\left[T_{A}, 1\right]$, choosing promises from $\left[T_{A}, 1\right]$ over those from $\left[0, T_{A}\right)$.

Note that in this class of equilibria (and in contrast to the promiseseparating equilibrium discussed earlier), altruists cannot be expected to transfer more than their bliss point $T_{A}$. To see this, suppose the altruist is expected to transfer $t_{A}^{\prime}=T_{A}+\varepsilon$. An elected altruist would be faced with an expectation of $\tau(y)=f_{S}\left(T_{S}+\gamma / 2\right)+f_{A}\left(T_{A}+\varepsilon\right)$, which is strictly less than $T_{A}+\varepsilon$ for clearly separated types and any positive probability $f_{S}$ of there being a selfish candidate. But then, given $T_{A}<T_{A}+\varepsilon$, the altruist could gain by choosing a transfer $t_{A}^{\prime \prime}$ with $\left\{\max \left\{\tau(y), T_{A}\right\}<t_{A}^{\prime \prime}<t_{A}^{\prime}\right.$. As expectations are required to be rational, this cannot constitute an equilibrium. By an analogous argument, it can be easily shown that it cannot be optimal for selfish types to transfer $t_{S}^{\prime}$ such that $t_{S}^{\prime}<T_{S}+\gamma / 2$.

\subsubsection{Nonseparated Types}

In this section, we briefly present the case of nonseparated types, in the sense of $T_{A}<T_{S}+\gamma / 2$. The arguments leading to the findings of this section are in close analogy to those in the preceding section and therefore, omitted. With respect to the conditions for a promise-separating equilibrium to exist (with $y_{i}=t_{i}=T_{i}+\gamma / s$ ), we note that they are the same as under clearly separated types. Specifically, Equation (3) must hold. However, the restriction on the guilt-aversion parameter will be higher as $\left(T_{A}-T_{S}\right)$ diminishes. More specifically, if $T_{S}$ and $T_{A}$ are close enough, the restriction to be imposed on $\gamma$ for a promise-separating equilibrium to exist will be prohibitively strong.

As promise-pooling equilibria are concerned under the given assumption on voter beliefs, there are three changes: (i) the support of candidates' promise-generating process will change to $\left[T_{A}+\gamma / 2,1\right]$, (ii) beliefs will change to $\hat{\tau}(y)=\tau(y)=T_{S}+\gamma / 2$, but most importantly, we will (iii) observe a pooling also in transfers, at the maximum a selfish type would be willing to transfer, that is, $t_{i}=T_{S}+\gamma / 2, \forall i \in\{A, S\}$.

\subsection{Hypotheses}

In the preceding, we have sketched a simple model of candidate behavior with guilt-aversion and two social-preference types. This model may give rise to promise-separating equilibria with general adherence to second-order beliefs; however, the scope for such equilibria diminishes rapidly the closer potential candidates are in terms of their social preferences. Due to this fact, we argue that promise-pooling equilibria are a more realistic scenario. In these promise-pooling equilibria, all candidates will promise at least the altruist's bliss-point transfer, that is, $y_{i} \geq T_{A}, i \in\{A, S\}$. By players' utility function given in equation (1), it is immediately obvious that in our RAND-P game, this cannot be optimal. Given promises do not have consequences for candidate selection, under random selection we must obtain $y_{i} \leq T_{i}, i \in\{A, S\}$. 
Combining the two facts, it is clear that average promises are predicted to be lower in RAND-P than in Vote-P:

H1. Promises are lower under random appointment of candidates than when there is a vote coupled with electoral promises.

When it comes to transfer choices, we have a similar picture: in the VOTE-P game, selfish candidates will choose transfers that are higher than their bliss point, whereas altruistic candidates may or may not do so. In RAND-P, on the other hand, there is no reason for why successful candidates should deviate from their bliss point. Thus, we directly obtain.

H2. Average transfers are higher under a voting mechanism with agenda-specific promises than under random appointment.

Finally, we assumed rational expectations. In other words, voters in VOTE-P will correctly predict lower transfers as compared to promises; at the same time, they will predict higher transfers than their counterparts in RAND-P. Dictators' second-order beliefs will match voters' expectations.

H3. Dictators' second-order beliefs and voters first-order beliefs match, at the (weighted-)average level of dictator types' transfers.

Having discussed the predictions for our P-games against the backdrop of our simple model sketch, we now proceed to discuss our research hypotheses for the D-games.

\subsection{Behavioral Hypotheses}

Bohnet and Frey (1999) show that diminishing social distance between dictators and recipients leads to more generous choices by the former in dictator games. Hoffman, McCabe, and Smith $(1996,1999)$ argue that this may be driven by some implicit form of reciprocal behavior. In light of these studies, we predict that dictator's choices will be more generous in our VOTE-D treatment when compared to RAND-D: not only is there more of a common history connecting selected candidates and their voter-recipients, but the dictator may attach a positive connotation to this history, as each vote for a candidate can be interpreted as a signal of social appraisal. If the enhancement of generous choices by diminished social distance has an underlying reciprocity motive and the vote conveys social appraisal, the following hypothesis can be postulated.

\section{H4. Transfers are higher in VOTE-D than in RAND-D .}

Note that this hypothesis could easily be incorporated into the model broadly delineated above by adding a conditional good-will parameter to dictators' bliss points. This parameter would simply shift the bliss point by a certain number $k$ if the player is elected. Given players only get to choose a 
transfer if they are elected, incorporating the additional parameter would merely shift the values of bliss points, transfers, and beliefs by the same amount $k$, without affecting the nature of the analysis.

The voting procedure may also affect recipients' expectations of the behavior of the chosen dictator. First, if Hoffman, McCabe, and Smith's (1996, 1999) implicit-reciprocity conjecture is correct, voters may expect elected dictators to behave reciprocally and in a group-oriented manner in response to the social appraisal they have experienced. Second, recipients in Vоте-D decide on who will be elected, which may make them feel less vulnerable with respect to the dictator, compared to recipients in RAND-D. Research in social psychology on the "illusion of control" (Langer 1975) has shown that participatory procedures may make people more confident about personal success in uncertain situations even when the objective probabilities of success have not changed. Translated into our design, recipients may trust more in the group-oriented behavior of the dictator in VOTE-D than in RAND -D even if $\mathrm{H} 4$ proves to be incorrect merely because they are able to choose.

H5. Recipients expect higher transfers in Vote-D than in RAND-D .

\section{Results}

Table 1 reports summary statistics of the main variables measured in our experiment. In the upper part of Table 1, we compare the mean transfers of dictators across treatments. Surprisingly, average transfers seem lower in Vote-D than in RAND-D both in China (29.94 vs. 34.80) and in Germany (38.30 vs. 49.70 ), contrary to our hypothesis H4. However, both differences are far from being significant $\left(p=0.624\right.$ and 0.424 , respectively) ${ }^{12}$ Therefore, we can state our first result.

Result 1 . The mere presence of a voting mechanism without electoral promises does not lead to more generous transfers.

Furthermore, there are no significant differences between average transfers in the German and the Chinese D-sessions $(p=0.229$ for Vote-D, $p=0.115$ for RAND-D). ${ }^{13}$ Similarly, there is a substantial but insignificant difference between the RAND-treatments $(p$ $=0.111$ ) which may arise from the slight relaxation of dictators' anonymity resulting from the disclosure of personality descriptions. With respect to the comparison between transfers in the VOTE-P and

\footnotetext{
${ }^{12}$ Unless otherwise indicated, all comparisons are based on two-sided Mann-Whitney $U$ tests.

${ }^{13}$ We also tested for a significant difference between Vote-D-RAND-D treatment differences in China and Germany by means of the Monte-Carlo approximation of a two-sided permutation test with 50,000 draws. The test does not reveal a significant difference, with $p=0.560$.
} 
Table 1: Dictators promises and transfers, recipients beliefs about transfers

\begin{tabular}{lccc}
\hline & & Vote & Rand \\
\hline P-games (China) & Mean transfers & 34.00 & 25.30 \\
& & $(17.592)$ & $(20.303)$ \\
D-games (China) & & 29.93 & 34.80 \\
& & $(17.248)$ & $(17.877)$ \\
D-games (Germany) & & 38.30 & 49.70 \\
& & $(13.873)$ & $(24.221)$ \\
P-games (China) & Mean promise of dictators & 52.25 & 49.75 \\
& & $(7.887)$ & $(13.396)$ \\
& & 40.75 & 36.70 \\
& Dictators' second-order beliefs & $(11.616)$ & $(16.658)$ \\
& (beliefs with respect to & \\
& voters' expected transfers) & 40.99 & 34.13 \\
D-games (China) & Mean expected transfers & $(9.954)$ & $(10.095)$ \\
& & 41.20 & 39.62 \\
D-games (Germany) & & $(7.578)$ & $(14.796)$ \\
& & 35.03 & 40.53 \\
& & $(8.972)$ & $(4.110)$ \\
\hline
\end{tabular}

Note: Standard deviation in parentheses.

RAND-P games, we observe a substantial difference that is weakly significant $(p=0.098)$. If we pool actual transfers and hypothetical transfers of non-selected candidates, the difference becomes significant $(p=0.050) \cdot{ }^{14}$ In other words, hypothesis H2 is largely supported by the data.

Result 2. When coupled with electoral promises, a voting mechanism increases transfers.

The average beliefs of recipients about dictator transfers are summarized in the lower part of Table 1 . Beliefs are very similar in the Chinese sessions of the D-games (41.20 vs. $39.62, p=0.992$ ), but weakly significantly different in the German D-sessions: surprisingly and contrary to our hypothesis H5, German recipients' expectation with respect to their dictators' transfer choices is weakly significantly higher in RAND-D than in VOTE-D (40.53 vs. 35.03,

\footnotetext{
${ }^{14}$ As mentioned earlier, hypothetical transfers were elicited in a way so as to blur their hypothetical nature, cf. footnote 6 . Also, there was no difference in the information given to selected and non-selected candidates except for the formers' certainty about having succeeded. Finally, the data do not give a clear indication against a pooling of data ( $p$ values for a comparison of hypothetical and actual transfers are $p=0.738$ for VOTE-P and $p=0.341$ for RAND-P). Clearly, none of the above can be seen as a strong argument in favor of pooling. For this reason, we provide both the pooled and nonpooled results.
} 
$p=0.069) .{ }^{15}$ So, in contrast to recipients drawn from a Chinese subject pool, German recipients tend to expect to receive higher transfers when their dictator is randomly chosen than when the dictator is chosen by a vote based on a personality description.

In the P-games, on the other hand, recipients tend to expect higher transfers when there is a vote that is coupled with numerical promises in the electoral campaign ( 40.99 vs. $34.13, p=0.081$ ). This is in line with the predictions of our simple signaling model. At the same time and addressing hypothesis H3, dictators' secondorder beliefs match recipients' expectations surprisingly well (40.75 vs. $40.99, p=0.914$, in Vote-P, and 36.70 vs. $34.13, p=0.964$, in RAND-P). Nevertheless, they are substantially (even though insignificantly) higher than dictators' transfers (40.99 vs. $34.00, p=0.139$, in Vote-P, and 34.13 vs. 25.30, $p=0.136$ ), even though recipients correctly predict highly significantly lower transfers compared to promises (40.99 vs. 52.25 in Vote-P, and 34.13 vs. 49.75 in RAND-P, both $p<0.001$; all but the first comparison in this paragraph rely on Wilcoxon signed-rank tests).

Result 3. Voters correctly predict transfers to be lower than promises although they still overestimate the correlation between dictators' promises and their transfers. Dictators seem to anticipate this: their second-order beliefs match recipients' expectations closely.

Interestingly, promises in the P-treatments do not follow the pattern predicted by our model. Contrary to hypothesis $\mathrm{H} 1$, there is no difference in the average promise of candidates who were elected and those who were chosen by a random draw ( 52.25 vs. $49.75, p=$ 0.297 ). At the same time, there is a substantial correlation between promises and transfers in Vote-P (Spearman's $\varrho=0.404, p=$ $0.078)$, whereas there is no such correlation in RAND-P $(\varrho=-0.072$, $p=0.763)$. One possible explanation for such a difference in the relationship between promises and transfers may be guilt-aversion, if a vote changes the way in which second-order beliefs are linked to promises. Indeed, we find such a difference. Dictators in Vote-P expect their electorate to believe in a strong relationship between promises and actions: their promises and second-order beliefs are strongly correlated $(\varrho=0.662, p=0.001)$. In RAND-P, this correlation is much weaker $(\varrho=0.372, p=0.106) .{ }^{16}$ At the same time, the correlation between second-order beliefs and transfers is almost

\footnotetext{
${ }^{15}$ Testing for recipients' expectations on the hypothetical transfers of the unselected candidates yields even clearer results $(42.27$ vs. $34.27, p=0.007)$.

${ }^{16}$ The difference between second-order beliefs of 40.75 vs. 36.7 fails to reach significance, $p=0.158$. Although this cannot be counted as strong support for our hypothesized mechanism, it is not an argument against it, either.
} 
comparable $(\varrho=0.408, p=0.074$ for Vote-P, $\varrho=0.374, p=0.104$ for RAND-P).

Result 4. Running for office in a contested election does not per se lead to higher promises. However, it generates a correlation between promises and transfers that does not exist when dictators are designated randomly.

\section{Discussion and Conclusion}

In the preceding section, we have seen that a voting mechanism leads to higher transfers if and only if it is coupled with electoral promises concerning the future choices of candidates (Results 1 and 2). Contrary to the implicit-reciprocity hypothesis of Hoffman, McCabe and Smith (1996, 1999), the social appraisal of a candidate's personality implied in the candidate's election does not induce, by itself, more generous behavior on the part of successful candidates. Rather, it seems as if there is a tendency for a personality-based vote to decrease dictators' generosity, even though this tendency is far from being statistically significant. Nevertheless, the fact that we observe this tendency in both subject pools and that in our German sessions, recipients expect this shift in generosity to happen suggests there may be more to it than mere chance. ${ }^{17}$

A possible explanation for the above pattern is that the personality vote leads to a stronger feeling of entitlement (Hoffman et al. 1994), which in turn may lead to power being exercised in a more self-oriented way. Possibly, elected dictators consider their election as their constituency's consent to a self-biased use of power or as the victory in a competition for a prize that consists of claims on the resource to be distributed. Earlier studies have shown that giving-behavior in dictator games reacts sensitively to how entitled the dictator feels to keeping the amount to be distributed between herself and the recipient: dictators give considerably less if they earned the money, for example by passing a test (Cherry, Frykblom, and Shogren 2002). Even subtle forms of entitlements seem to matter: in Bolle and Vogel (2008), provisional allocations (by the experimenter) between the dictator and the recipient influence the final allocation of the dictator as long as the provisional allocation is privately and socially acceptable. Hence, if the personality vote leads to a stronger sense of entitlement than random selection, one may expect dictators' generosity to be lower in VOTE-D than in RAND-D. To the best of our knowledge, entitlements have not been considered explicitly in voting experiments. Indeed, entitlements may matter more in our design than

\footnotetext{
${ }^{17}$ Interestingly enough, when asked in the postexperimental questionnaire whether they preferred a voting or a random procedure to select the candidate, recipients in both Dtreatments nevertheless voiced a preference for the voting procedure (the fraction preferring the vote is different from $1 / 2$ by a Chi-square goodness-of-fit test with $p<0.07$ for all D-treatments). This seems to be in line with the notion of procedural utility (see, e.g., Frey, Benz, and Stutzer 2004): recipients seem to have a taste for having a say.
} 
in previous voting studies. In Walkowitz and Weiss (2011) and Corazzini et al. (2007), allocators are elected based on specific promises on their behavior in the position of the allocator. No personal information is given about the candidates. Hence, elected allocators are likely to be aware that their electoral success was due to their promises and not to them being the "better" candidate.

If campaigns consist of clear promises with respect to the candidates' prospective choices, elected dictators transfer more to their group than randomly drawn dictators (Result 2). Contrary to the findings of Corazzini et al. (2007) and our hypothesis H4, however, this does not come with higher electoral promises. This fact allows us to reject one possible explanation of their results-at least for our subject pool. It is not the case that transfers in a voting environment are higher because promises are driven up by political competition and dictators adhere to promises. Rather, the correlation between dictators' promises and their second-order beliefs is much stronger. This suggests that a vote may compel dictators to fulfill their promises because it changes second-order beliefs, which would be in line with the guilt-aversion hypothesis. Overall, our simplistic guilt-aversion model seems to organize the data from the P-games rather well: the correlation between promises and second-order beliefs is strong only in the voting treatment, whereas the correlation between second-order beliefs and transfers is almost as strong in RAND-P as in Vote-P. Consequently, transfers are higher under voting. Moreover, recipients anticipate low transfers and dictators' second-order beliefs are correct. And yet, transfers fall short of recipients' expectations, contrary to our theoretical prediction. This means that voter beliefs with respect to the power-limiting effects of voting are overly optimistic — which could be explained by the illusion-of-control hypothesis from social psychology (Langer 1975) — and dictators knowingly let them down. In other words, the model fails in at least one of two ways: (i) the assumption of an equilibrium in beliefs is too strong and (ii) the power of guilt-aversion to shape behavior is over-estimated. Having said that, we also note that guilt-aversion is likely to play an important role in the context under examination: "costs of lying" or a "taste for consistency," being the main alternative explanations for behavior in situations involving promises (cf. the current discussion between Charness and Dufwenberg 2006, 2010, Vanberg 2008, Ellingsen et al. 2010), cannot account for the central result that transfers are higher under the voting mechanism (Result 2) even though promises do not differ (Result 4). Therefore, our paper contributes to this lively debate, suggesting that there clearly is a role for guilt-aversion, even though this role is smaller than initially suggested by the guilt-aversion model as introduced by Charness and Dufwenberg (2006).

To come back to our main research question, our results suggest that a voting mechanism as such is not enough to limit the opportunistic use of power by elected candidates. Rather, it seems as if being elected on the basis of one's personality induces a stronger sense of entitlement, leading to 
less welfare-oriented behavior. Once we couple the voting mechanism with promises about prospective in-office behavior, we observe a beneficial effect of elections. However, this effect is not as strong as expected. Taken together, these findings seem to suggest that for elections to unfold their full potential as a power-limiting device, re-election concerns are indispensable. At the same time, real-world electoral campaigns are often based on candidates' personalities as well as on their promises for in-office behavior. A possible interaction of an entitlement effect and promises therefore seems to be an interesting avenue for future research.

\section{Appendix: Experimental Instructions}

\section{General Instruction}

Welcome to our experiment!

Please read through the instructions carefully. You are not allowed to communicate with other participants by any means during the experiment.

If you are not clear about the experiment, please read through the instructions once again. For any further questions please raise your hand and we will come to answer your questions individually.

Your payoff will be expressed in points. The amount of the points depends on the decisions made by you and the other participants. After the experiment, we will exchange the points into RMB/Euro according to the following exchange rate:

$$
100 \text { Points }=75 \text { RMB } / 18.75 \text { Euro. }
$$

Besides, each participant will receive $10 \mathrm{RMB} / 4$ Euro for participating in the experiment.

During the whole experiment, please make the decision on your own. Be sure not to communicate with other participants in any way, or else you have to be ruled out of the experiment.

All the data and answers will be analyzed anonymously. To ensure anonymity, you have been instructed to choose a code number. Please find your seat in the cabinet with the corresponding number and make your own decision during the experiment. We can match decisions only to code numbers, but not to persons.

\section{A.1. Instruction for the Treatment VoTE-D}

There are 25 participants in the experiment.

This Experiment has only one round!

At the beginning of the experiment, each participant is allocated randomly into a five person group. The decisions within each group are independent of the other groups, that is to say, your decision only influences 
your own group members. There are two types of players in each group: three participants are citizens and the other two are candidates. One of the two candidates will be elected by the three citizens to be the president.

The elected president decides on how to distribute 100 points among the citizens in his group and himself. He can arbitrarily distribute the 100 points between him and the citizens of his group. The president decides how many of the 100 points he will transfer to each citizen in his group. The payoff for the president is the difference between the 100 points and the amount he transferred to the citizens. The amount transferred to each citizen is identical, that is, each citizen receives the same amount from the president.

The citizens vote for the president in the following way

The two candidates choose among eight descriptive adjectives those three that best represent his personality and rank them according to how well the adjectives describe his personality. (The first one is the adjective that best explains his personality, the second one is the second suitable adjective for his personality and the third one represents the third adjective matching his personality.) These three ranked adjectives are the personality statements of the candidates.

The citizens see the personality statements of the two candidates and elect one of them to become the president. Each citizen has only one vote and the voting result is determined by majority rule, that is, the candidate with at least two votes becomes the president. The elected president then makes the allocation decision as described earlier.

\section{The steps of the experiment:}

(i) At the beginning of the experiment, each participant is randomly allocated to a five person group and receives the role either as a citizen or as a candidate.

(ii) Each candidate chooses three descriptive adjectives that best represent his personality among the eight descriptive adjectives and rank them according to the conformity of the adjectives with his personality.

(iii) Citizens see the personality statement of the candidates and elect one of them to become the president.

(iv) The elected president makes the transfer decision.

(v) Each group member is informed on his own payoff.

(vi) The experiment ends.

How to calculate your payoff in the experiment?

(i) Citizen: Citizen's payoff $=$ amount transferred by the president.

The payoff of each citizen is equal to the amount transferred by the president. The higher the amount is, the higher will be his payoff; the lower this amount is, the lower will be his payoff. 
(ii) President: President's payoff $=100-$ amount transferred to the citizens. The payoff of the president is equal to the difference between 100 points and the amount he transferred to the citizens. The higher this amount is, the lower will be his payoff; the lower the amount is, the higher will be his payoff.

(iii) Payoff of the unelected candidate: The computer draws one number from the interval $\{0,1, \ldots, 100\}$. This number is the payoff of the unelected candidate.

\section{A.2. Instruction for the Treatment RAND-D}

There are 25 participants in the experiment.

This Experiment has only one round!

At the beginning of the experiment, each participant is allocated randomly into a five person group. The decisions within each group are independent of the other groups, that is to say, your decision only influences your own group members. There are two types of players in each group: three participants are citizens and the other two are candidates. One of the two candidates will be randomly selected to be the president.

The randomly selected president decides on how to distribute 100 points among the citizens in his group and himself. He can arbitrarily distribute the 100 points between him and the citizens of his group. The president decides how many of the 100 points he will transfer to each citizen in his group. The payoff for the president is the difference between the 100 points and the amount he transferred to the citizens. The amount transferred to each citizen is identical, that is, each citizen receives the same amount from the president.

How to randomly select the president.

A computer program select randomly one of the two candidates to be president. The two candidates choose among eight descriptive adjectives those three that best represent his personality and rank them according to how well the adjectives describe his personality. (The first one is the adjective that best explains his personality, the second one is the second suitable adjective for his personality and the third one represents the third adjective matching his personality.) These three ranked adjectives are the personality statements of the candidates.

The citizens see the personality statements of the two candidates and know which one of them is randomly selected to be the president.

The steps of the experiment:

(i) At the beginning of the experiment, each participant is randomly allocated to a five person group and receives the role either as a citizen or as a candidate. 
(ii) Each candidate chooses three descriptive adjectives that best represent his personality among the eight descriptive adjectives and rank them according to the conformity of the adjectives with his personality.

(iii) Citizens see the personality statement of the candidates and know which one of them is randomly selected to be the president.

(iv) The randomly selected president makes the transfer decision.

(v) Each group member is informed on his own payoff.

(vi) The experiment ends.

How to calculate your payoff in the experiment?

(i) Citizen: Citizen's payoff = amount transferred by the president. The payoff of each citizen is equal to the amount transferred by the president. The higher the amount is, the higher will be his payoff; the lower this amount is, the lower will be his payoff.

(ii) President: President's payoff $=100-$ amount transferred to the citizens. The payoff of the president is equal to the difference between 100 points and the amount he transferred to the citizens. The higher this amount is, the lower will be his payoff; the lower the amount is, the higher will be his payoff.

(iii) Payoff of the unselected candidate: The computer draws one number from the interval $\{0,1, \ldots, 100\}$. This number is the payoff of the unselected candidate.

\section{A.3. Instruction for the Treatment VOTE-P}

There are 25 participants in the experiment.

This experiment has only one round!

At the beginning of the experiment, each participant is allocated randomly into a five person group. The decisions within each group are independent of the other groups, that is to say, your decision only influences your own group members. There are two types of players in each group: three participants are citizens and the other two are candidates. One of the two candidates will be elected by the citizens to be president.

The elected president decides on how to distribute 100 points among the citizens in his group and himself. He can arbitrarily distribute the 100 points between him and the citizens of his group. The president decides how many of the 100 points he will transfer to each citizen in his group. The payoff for the president is the difference between the 100 points and the amount he transferred to the citizens. The amount transferred to each citizen is identical, that is, each citizen receives the same amount from the president.

The citizens vote for the president in the following way.

The two candidates make promises about how many points they are going to distribute to the citizens if they win the election. 
The citizens see the promises of the two candidates and elect one of them to become the president. Each citizen has only one vote and the voting result is determined by majority rule, that is, the candidate with at least 2 votes becomes the president. The elected president then makes the allocation decision as described above.

The steps of the experiment:

(i) At the beginning of the experiment, each participant is allocated to a five person group at random and receives the role either as a citizen or as a candidate.

(ii) Each candidate makes a promise about how many points he will allocate to the citizens if he wins the election.

(iii) Each citizen sees the promises of the candidates and votes for one of them for presidency.

(iv) The elected president makes the transfer decision.

(v) Each group member is informed of his own payoff.

(vi) The experiment ends.

How to calculate your payoff in the experiment?

(i) Citizen: Citizen's payoff $=$ amount transferred by the president . The payoff of each citizen is equal to the amount transferred by the president. The higher the amount is, the higher will be his payoff; the lower this amount is, the lower will be his payoff.

(ii) President: President's payoff $=100-$ amount transferred to the citizens. The payoff of the president is equal to the difference between 100 points and the amount he transferred to the citizens. The higher this amount is, the lower will be his payoff; the lower the amount is, the higher will be his payoff.

(iii) Payoff of the unelected candidate: The computer draws one number within the interval $\{0,1, \ldots, 100\}$. This number is the payoff of the unelected candidate.

\section{A.4. Instruction for the Treatment RAND-P}

There are 25 participants in the experiment.

This experiment has only one round!

At the beginning of the experiment, each participant is allocated randomly into a five person group. The decisions within each group are independent of the other groups, that is to say, your decision only influences your own group members. There are two types of players in each group: three participants are citizens and the other two are candidates. One of the two candidates will be selected to be president randomly by computer.

The randomly selected president decides on how to distribute 100 points among the citizens in his group and himself. He can arbitrarily distribute the 100 points between him and the citizens of his group. The president decides 
how many of the 100 points he will transfer to each citizen in his group. The payoff for the president is the difference between the 100 points and the amount he transferred to the citizens. The amount transferred to each citizen is identical, that is, each citizen receives the same amount from the president.

\section{How to randomly select the president:}

The two candidates make promises about how many points they are going to distribute to the citizens if they win the election. The citizens see the promises of the two candidates. Computer program selects randomly one of the two candidates to be president. The selected president then makes the allocation decision as described earlier.

The steps of the experiment:

(i) At the beginning of the experiment, each participant is allocated to a five person group at random and receives the role either as a citizen or as a candidate.

(ii) Each candidate makes a promise about how many points he will allocate to the citizens if he becomes the president.

(iii) Each citizen sees the promises of the candidates and knows which one of them is randomly selected to be the president.

(iv) The selected president makes the transfer decision.

(v) Each group member is informed of his own payoff.

(vi) The experiment ends.

How to calculate your payoff in the experiment?

(i) Citizen: Citizen's payoff = amount transferred by the president.

The payoff of each citizen is equal to the amount transferred by the president. The higher the amount is, the higher will be his payoff; the lower this amount is, the lower will be his payoff.

(ii) President: President's payoff $=100-$ amount transferred to the citizens. The payoff of the president is equal to the difference between 100 points and the amount he transferred to the citizens. The higher this amount is, the lower will be his payoff; the lower the amount is, the higher will be his payoff.

(iii) Payoff of the unselected candidate: The computer draws one number within the interval $\{0,1, \ldots, 100\}$. This number is the payoff of the unselected candidate.

\section{References}

BARDHAN, P. K., and T. T. YANG (2004) Political competition in economic perspective. Working Paper, University of California at Berkeley.

BATTIGALLI, P., and M. DUFWENBERG (2007) Guilt in games, American Economic Review 97(2), 170-176. 
BESLEY, T. (2005) Political selection, Journal of Economic Perspectives 19(3), 43-60.

BOHNET, I., and B. S. FREY (1999) Social distance and other-regarding behavior in dictator games: Comment, American Economic Review 89(1), 335-339.

BOLLE, F., and C. VOGEL (2008) Power comes with responsibility - or does it? Working Paper, University of Frankfurt (Oder).

CARRILLO, J. D., and T. MARIOTTI (2001) Electoral competition and politician turnover, European Economic Review 45(1), 1-25.

CHARNESS, G., and M. DUFWENBERG (2006) Promises and partnership, Econometrica 74(6), 1579-1601.

CHARNESS, G., and M. DUFWENBERG (2010) Bare promises: An experiment, Economics Letters 107, 281-283.

CHERRY, T. L., P. FRYKBLOM, and J. F. SHOGREN (2002) Hardnose the dictator, American Economic Review 92(4), 1218-1221.

COOTER, R. (2003) Who gets on top in democracy-elections as filters, Supreme Court Economic Review 10, 127-141.

CORAZZINI, L., S. KUBE, and M. A. MARÉCHAL (2007) Towards behavioral public choice: Guilt aversion and accountability in the lab. Working Paper, Max Planck Institute for Research on Collective Goods.

DAL BÓ, P., A. D. FOSTER, and L. G. PUTTERMAN (2008) Institutions and behavior: experimental evidence on the effects of democracy. Working Paper, Brown University.

ELLINGSEN, T., and M. JOHANNESSON (2004) Promises, threats and fairness, The Economic Journal 114, 397-420.

ELLINGSEN, T., M. JOHANNESSON, S. TJØTTA, and G. TORSVIK (2010) Testing guilt aversion, Games and Economic Behavior 68(1), 95-107.

FISCHBACHER, U. (2007) z-Tree: Zurich toolbox for ready-made economic experiments, Experimental Economics 10(2), 171-178.

FORSYTHE, R., J. HORROWITZ, N. SAVIN, and M. SEFTON (1994) Fairness in simple bargaining experiments, Games and Economic Behavior 6, 347-369.

FREY, B. S., M. BENZ, and A. STUTZER (2004) Introducing procedural utility: not only what, but also how matters, Journal of Institutional and Theoretical Economics 160, 377-401.

GEANAKOPLOS, J., D. PEARCE, and E. STACCHETTI (1989) Psychological games and sequential rationality, Games and Economic Behavior 1(1), 60-79.

GÜRERK, Ö., B. IRLENBUSCH, and B. ROCKENBACH (2006) The competitive advantage of sanctioning institutions, Science 312, 108-111.

HOFFMAN, E., K. McCABE, K. SHACHAT, and V. L. SMITH (1994) Preferences, property rights, and anonymity in bargaining games, Games and Economic Behavior 7 (3), 346-380.

HOFFMAN, E., K. McCABE, and V. L. SMITH (1996) Social distance and other-regarding behavior in dictator games, American Economic Review 86(3), 653-660.

HOFFMAN, E., K. McCABE, and V. L. SMITH (1999) Social distance and otherregarding behavior in dictator games: Reply, American Economic Review 89(1), 340-341.

KING, A. (2002) Leader's Personalities and the Outcomes of Democratic Elections. Oxford: Oxford University Press.

LANGER, E. J. (1975) The illusion of control, Journal of Personality and Social Psychology 32, 311-328. 
LIPSITZ, K., C. TROST, M. GROSSMANN, and J. SIDES (2005) What voters want from political campaign communication, Political Communication 22(3), 337-354.

LOCKE, J. (1988) Two Treatises of Government. P. Lastett, ed. Cambridge, UK: Cambridge University Press.

MASKIN, E., and J. TIROLE (2004) The politician and the judge: accountability in government, American Economic Review 94(4), 1034-1054.

MAIER-RIGAUD, F. P., and J. APESTEGUIA (2003) The role of choice in social dilemma experiments. Working Paper, Max Planck Institute for Research on Collective Goods.

MILLER, A. H., M. P. WATTENBERG, and O. MALANCHUK (1986) Schematic assessments of presidential candidates, The American Political Science Review 80 (2), $521-540$.

OSTROM, E., J. WALKER, and R. GARDNER (1992) Covenants with and without a sword: Self-governance is possible, The American Political Science Review 86(2), 404-417.

SELTEN, R. (1967) Die Strategiemethode zur Erforschung des eingeschränkt rationalen Verhaltens im Rahmen eines Oligopolexperiments, in Beitrage zur exprimentellen Wirtschaftsforschung, H. Sauermann, ed., pp. 136-168.Tübingen: Mohr Siebeck Verlag.

STOKES, D. E. (1966) Some dynamic elements of contests for the presidency, The American Political Science Review 60 (1), 19-28.

TYRAN, J.-R., and L. P. FELD (2006) Achieving compliance when legal sanctions are non-deterrent, Scandinavian Journal of Economics 108(1), 135-156.

VANBERG, C. (2008) Why do people keep their promises? An experimental test of two explanations, Econometrica 76(6), 1467-1480.

WALKOWITZ, G., and A. WEISS (2011) Is voting good for voters? Experimental evidence on reciprocity and promise-keeping. Working Paper, University of Cologne.

WEISS, A. (2011) The economic virtues of voting - how political competition limits confiscatory behaviour. Working Paper, University of Cologne. 